Proc. VII National Conference of Neutron Scattering and Complementary Methods, Chlewiska, Poland, June 12-16, 2011

\title{
X-Ray Diffraction and Electron Microscopy Studies on the Structure of Thermal Barrier Coatings
}

\author{
L. GÓRSKI ${ }^{a}$ AND A. PAWŁOWSKI ${ }^{b}$ \\ ${ }^{a}$ National Centre for Nuclear Research, A. Sołtana 7, 05-400 Otwock-Świerk, Poland \\ ${ }^{b}$ Institute of Metallurgy and Material Sciences, Polish Academy of Sciences \\ W.S. Reymonta 25, 30-959 Kraków, Poland
}

\begin{abstract}
Composites based on $\mathrm{Al}_{2} \mathrm{O}_{3}$ and $\mathrm{ZrO}_{2}$ are used. Coatings deposited by plasma spraying technology are studied with the use of X-ray diffraction and electron microscopy combined with electron diffraction methods. Phase transitions and specific coatings layered microstructure with local fluctuations of phase and chemical composition are connected with the conditions of plasma spray process.
\end{abstract}

PACS: $61.50 . \mathrm{Ks}, 81.30 .-\mathrm{t}$

\section{Introduction}

The presented studies are connected with the works on high temperature resistant protective coatings, especially thermal barrier coatings (TBC). These coatings are the result of advanced technology, combining suitable choice of the substrate, metallic bondcoat on $\mathrm{Ni}$ or Fe base (e.g. $\mathrm{NiCrAlY}$ ), and essential external ceramic layer based on $\mathrm{Al}_{2} \mathrm{O}_{3}$ and $\mathrm{ZrO}_{2}$. TBC due to insulated ceramics properties reduced the temperature attained by metal base components and acted as a barrier for erosion and corrosion effects caused by hot liquid and gaseous streams. Therefore these coatings have numerous applications among others in heat and gaseous turbines, aircraft and high compression engines [1-3].

TBC are deposited mainly by plasma spraying technology. Therefore two points should be taken under consideration. The first is connected with plasma spraying process (described in detail elsewhere). Its essential features are: short time high temperature action and high cooling rate. The time of material flight by the plasma arc with temperature of $10^{4} \mathrm{~K}$ range is about few $\mathrm{ms}$ which means that cooling rate of solidified material in the contact with a cold substrate is $10^{5}-10^{6} \mathrm{~K} / \mathrm{s}$ [4-6]. In such conditions different phase transitions other than in state of thermodynamic equilibrium with appearance of local amorphous, nanocrystalline and unordered phases may occur. Second factor is connected with the used materials. The main component of $\mathrm{TBC}$ is ceramic layer of composites based on $\mathrm{Al}_{2} \mathrm{O}_{3}$ and $\mathrm{ZrO}_{2}$ (both showing complex polymorphism). Thus the observed effects are caused by the process and material factors.

The purpose of performed works is of twofold character. First research side is to determine all changes in coatings structure and phase transitions occurring in the result of plasma spraying and coatings thermal treatment. The second practical side is to obtain coatings with increasing resistance as a thermal barrier.

\section{Experimental}

The studied coatings consist of two essential components.

Metallic bondcoat (thickness 100-200 $\mu \mathrm{m}$ ): $\mathrm{Cr}$ 15-20 wt\%, Al - 6-10 wt\%, Y - about 1\%, Ni - balance.

Ceramic composites (thickness 200-400 $\mu \mathrm{m}$ ):

1. $\mathrm{Al}_{2} \mathrm{O}_{3}+15 \% \mathrm{Cr}_{2} \mathrm{O}_{3}, 10-20 \mathrm{NiO}, 30 \% \mathrm{SiO}_{2}, 3-40 \%$ $\mathrm{TiO}_{2}, 40 \% \mathrm{ZrO}_{2}$,

2. $\mathrm{ZrO}_{2}+5-30 \% \mathrm{CaO}, 30 \% \mathrm{MgO}, 40 \% \mathrm{SrO}, 3-20 \% \mathrm{Y}_{2} \mathrm{O}_{3}$, $7-12 \%$ rare earth oxides composite.

Coatings are sprayed on superalloys substrates based on $\mathrm{Ni}$ or $\mathrm{Fe}$ by the method of atmospheric plasma spraying (APS) in $\mathrm{Ar}-\mathrm{H}_{2}$ plasma arc with the use of Polish plasmatrone PN-120 at Institute of Atomic Energy. The parameters and experimental details of this process are described elsewhere [4-6]. Two types of coatings thermal treatment are applied: annealing by the $50-100 \mathrm{~h}$ at 1200-1800 K and experiments with thermal shocks performed on special arrangement [4-6].

Coatings structure and phase transitions are studied by X-ray diffraction (XRD) methods using $\mathrm{Cu}$ and $\mathrm{Co}$ anode on the surface and on different coating depths. Layers stacking and sequence are observed firstly by the scanning electron microscope (SEM) and after special thinning methods by transmission electron microscopy (TEM) combined with selected area electron diffraction (SAED) with the use of CM20 TWIN electron microscope. Local composition analysis are performed by Link X-ray dispersion spectroscopy (EDS).

\section{Results and discussion}

X-ray diffraction patterns show coatings polycrystalline structure. In some cases the background of diffraction patterns is somewhat higher than that before spraying which may indicate for partial amorphisation and lower degree of ordering. In some composites 
phase transitions after plasma spraying appear whereas in other some effects of recrystallization with crystallite sizes change may be observed.

Coatings microstructure observed by SEM methods is characterized by the existence of numerous pores and microcracks. But either scanning microscope or X-ray diffraction give data involving coating surface or adjacent areas. We need however data about structure in nanometric range at deeper level especially from areas near to the interface ceramic-metal important for coating adherence and resistance. Therefore attempt of applying TEM methods combining with SAED was made. For obtaining sufficiently thin specimens special ion milling technique with the use of focused Ga ions beam (FIB) has been developed [7]. In the course of thinning possibilities of $\mathrm{X}$-ray study at various coating depths occur.

Coatings microstructure observed by TEM is rather complex. Several alternate layers amorphous, nanocrystalline and polycrystalline of equiaxial and columnar shape are remarked. These layers sometimes slightly differ from each other in chemical and phase composition. In some cases they are separated, in other may be partly mixed. The full description of performed studies is given among others in lately written monograph [6]. Some important results will be shown in the limited scope of this article.

\subsection{Composites based on $\mathrm{Al}_{2} \mathrm{O}_{3}$}

$\mathrm{Al}_{2} \mathrm{O}_{3}$ exists in several polymorphic forms. The main crystalline phase in coatings is metastable $\gamma$ form of spinel structure which after thermal treatment transforms into thermodynamic stable hexagonal $\alpha$ form (corundum) with possible intermediate forms. This phase transition is accompanied by density change (near $10 \%$ ) which causes coatings cracks and possible failure. Therefore composites with oxides listed in previous section are used in order to counteract such phase transition. These stabilisation trials gave in some cases interesting results particularly for $\mathrm{Al}_{2} \mathrm{O}_{3}-\mathrm{TiO}_{2}$ system. The increasing $\mathrm{TiO}_{2}$ amount to about $40 \%$ consistent with stoichiometric proportion 1:1 caused the occurrence of orthorhombic $\mathrm{Al}_{2} \mathrm{TiO}_{5}$.

This compound shows high thermal resistance especially for thermal shocks conditions due to low thermal expansion value and its anisotropy in different crystallographic directions [8].

However $\mathrm{Al}_{2} \mathrm{TiO}_{5}$ forms at higher temperature than thermal stable forms of separate oxides which was confirmed by differential thermal analysis (DTA) and differential scanning calorimetry (DSC) measurements [5]. It may be illustrated by diffraction patterns shown in Fig. 1. Material annealed at $1400 \mathrm{~K}$ contains single oxides: corundum and rutile (Fig. 1a), whereas annealed at $1800 \mathrm{~K}$ contains $\mathrm{Al}_{2} \mathrm{TiO}_{5}$ as a main phase with small amounts of single oxides (Fig. 1b).

This effect has a serious practical meaning due to strong difference in thermal shock resistance. Coatings with $\mathrm{Al}_{2} \mathrm{TiO}_{5}$ show only slight changes after 150 thermal

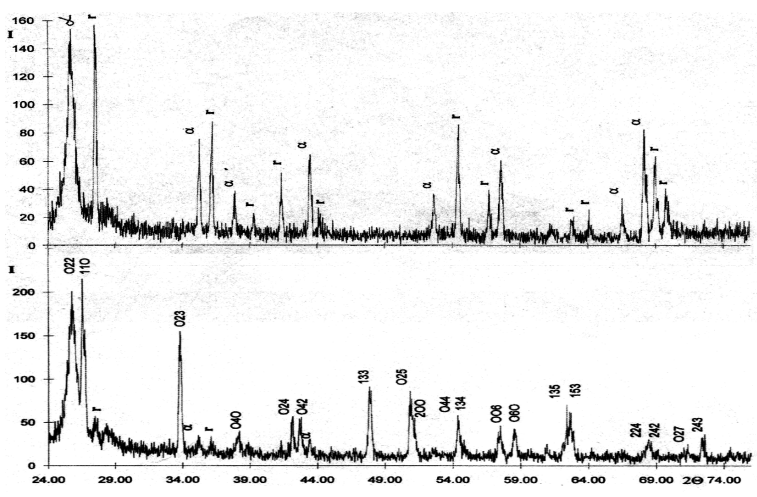

Fig. 1. Diffraction patterns, $\mathrm{Cu}$ radiation, (a) $\mathrm{Al}_{2} \mathrm{O}_{3}+$ $\mathrm{TiO}_{2}$, (b) $\mathrm{Al}_{2} \mathrm{TiO}_{5}, \alpha-\mathrm{Al}_{2} \mathrm{O}_{3}, r-$ rutile $\left(\mathrm{TiO}_{2}\right)$ indices listed for $\mathrm{Al}_{2} \mathrm{TiO}_{5}$.

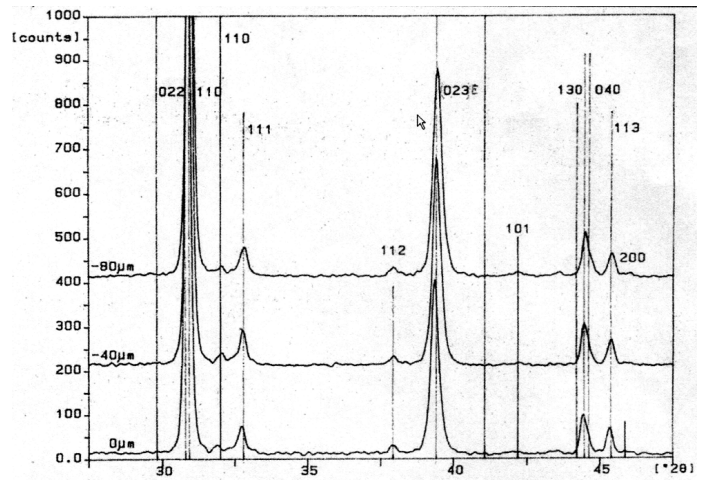

Fig. 2. Portion of diffraction pattern at surface and different coatings depths, Co radiation.

shock cycles but coatings with single oxides mixture are visibly damaged after $30-40$ cycles. Some materials supplied as aluminum titanate are really mixture of single oxides and therefore identification is in this case necessary.

In Fig. 2 portion of $\mathrm{Al}_{2} \mathrm{TiO}_{5}$ diffraction pattern at coating surface and different depths is shown. Only slight differences in peak intensities may be observed connected by the change of cooling conditions at coating surface (with contact of air) and interior (cooling by neighboring grains of insulated material).

The TEM images show also difference between simple oxides and $\mathrm{Al}_{2} \mathrm{TiO}_{5}$. In the first (Fig. 3) the disordered image is visible with numerous small crystals and characteristic contrast variety. SAED pattern (Fig. 3b) indicates for partly amorphous and microcrystalline areas with indexed rings and spots. For $\mathrm{Al}_{2} \mathrm{TiO}_{5}$ one can observe more ordered structure with visible columnar crystals (Fig. 4). The diffraction pattern (Fig. 4b) is also ordered. The appearance of rapidly solidified $\mathrm{Al}_{2} \mathrm{O}_{3}$ droplets is caused by above mentioned plasma spraying conditions.

In the $\mathrm{Al}_{2} \mathrm{O}_{3}-\mathrm{SiO}_{2}$ system the main phase is mullite $\left(3 \mathrm{Al}_{2} \mathrm{O}_{3}-2 \mathrm{SiO}_{2}\right)$ of orthorhombic symmetry stable to 


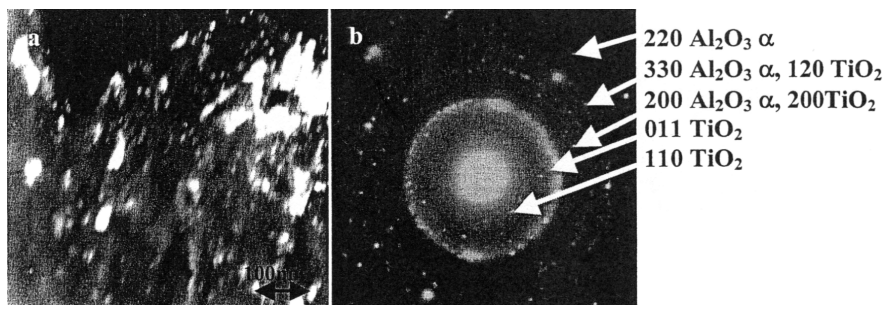

Fig. 3. TEM microstructure (a) with SAED pattern (b), suggesting oxide mixtures.

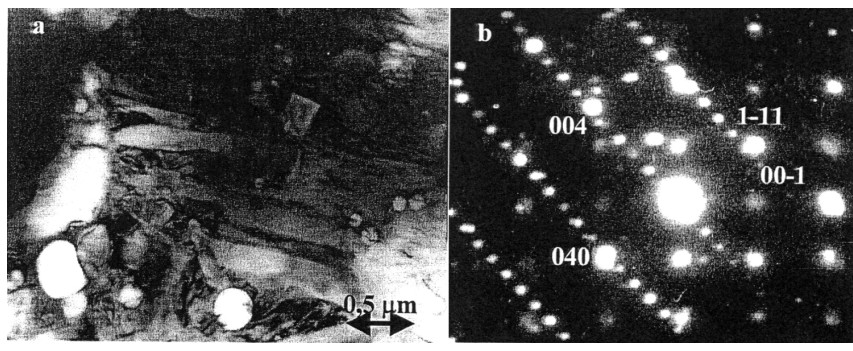

Fig. 4. Microstructure of $\mathrm{Al}_{2} \mathrm{TiO}_{5}$ coating (a) and corresponding diffraction pattern $(\mathrm{b})$ with rapidly solidified $\mathrm{Al}_{2} \mathrm{O}_{3}$ droplets.

plasma spraying and subsequent coatings thermal treatment. Neither change to another phase nor decomposition to simple oxides have been observed. The results for composites with mullite structure are already described in earlier works $[9,10]$. But it may be useful to notice some problems connected with two points. First is some kind of polytypism in mullite structure with appearance of primary and secondary form. Second is more amorphous sublayers which slowly transform into microcrystalline forms during annealing.

In the $\mathrm{Al}_{2} \mathrm{O}_{3}-\mathrm{ZrO}_{2}$ system composite containing 40 wt $\%$ of $\mathrm{ZrO}_{2}$ is investigation subject. It seems interesting by the connecting properties possibility of the main high temperature oxides. It is worth noting that $\mathrm{ZrO}_{2}$ is here without stabilizing additions. In powder before spraying both oxides as separate phases show presence of stable crystalline forms: $\alpha-\mathrm{Al}_{2} \mathrm{O}_{3}$ and monoclinic $\mathrm{ZrO}_{2}$. An interesting effect was observed in this case described in detail elsewhere [6, 11]. After spraying cubic and tetragonal $\mathrm{ZrO}_{2}$ occur which do not exist at ambient temperature without stabilizing additions. The content of these phases increases after coatings annealing. Similar effects are observed by Limarga and Miao for coatings deposited by sol-gel method [12, 13]. This effect of partial stabilization of cubic and tetragonal $\mathrm{ZrO}_{2}$ by the $\mathrm{Al}_{2} \mathrm{O}_{3}$ and its coexistence with monoclinic form should cause high thermal stability of these coatings. Thermal shock experiments confirming above suggestion are still in progress.

TEM images show alternate layers: amorphous, nano and polycrystalline. In Fig. 5a example of amorphous layer placed near to the interface with metallic bondcoat

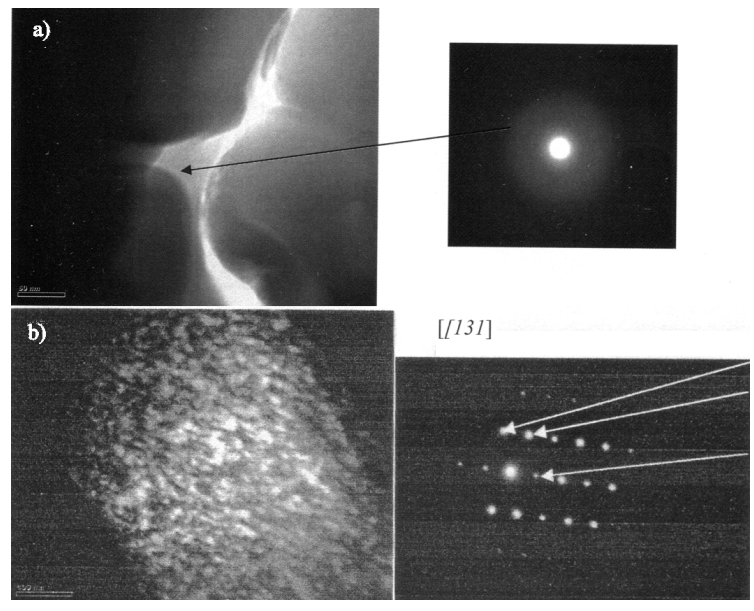

Fig. 5. TEM-SAED images: (a) amorphous layer, (b) crystalline $\alpha-\mathrm{Al}_{2} \mathrm{O}_{3}$ layer.

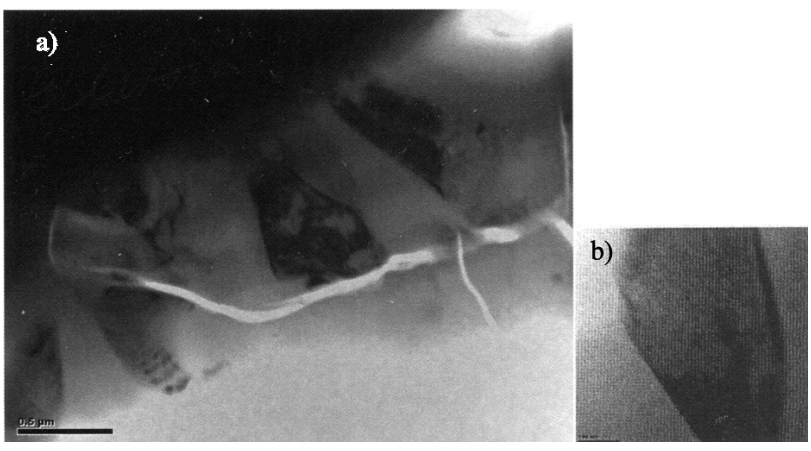

Fig. 6. (a) Columnar crystals within the ceramic layer, (b) enlarged image of individual crystal.

identified by electron diffraction can be seen. In this case the image contrast is different for amorphous (indicated by arrow) and surrounding crystalline layer. In Fig. 5b one can observe crystalline sublayer of $\alpha-\mathrm{Al}_{2} \mathrm{O}_{3}$ with indexed diffraction spots. Nearer to the coatings interior the areas of columnar crystals may be observed. Figure 6 a shows few such crystals. Enlarged image of single columnar crystal is shown in Fig. $6 \mathrm{~b}$.

\subsection{Composites based on $\mathrm{ZrO}_{2}$}

$\mathrm{ZrO}_{2}$ is a ceramic oxide with high melting point widely applied in high temperature technology. But it exists in few polymorphic forms. In order to counteract phase transition between them namely to stabilize cubic and tetragonal forms at wide temperature range some amounts of other oxides are added. The results of studies on composites listed in experimental part with resistance comparison are presented in other works $[5,6]$.

$\mathrm{Y}_{2} \mathrm{O}_{3}$ is regarded now as one of the best stabilizing addition to $\mathrm{ZrO}_{2}$ both in the bulk and coating form. Some problems are with its optimal content. Composites with $20 \% \mathrm{Y}_{2} \mathrm{O}_{3}$ contain stable cubic form but mechanical resistance is rather low due to brittle cracking. 
High resistance is shown by composites with $7-8 \% \mathrm{Y}_{2} \mathrm{O}_{3}$ named so-called partially stabilized zirconia (PSZ). This resistance is caused by the toughening effect owing to occurring some amount of monoclinic phase. This transformation is of martensite type but occurring in strictly limited range. To illustrate this effect two diffraction patterns are shown in Fig. 7. In the upper for coating as sprayed cubic form with slight tetragonal splitting is visible whereas in the second for coating after 60 thermal shocks the main phase remains but weak peaks of monoclinic form occur.

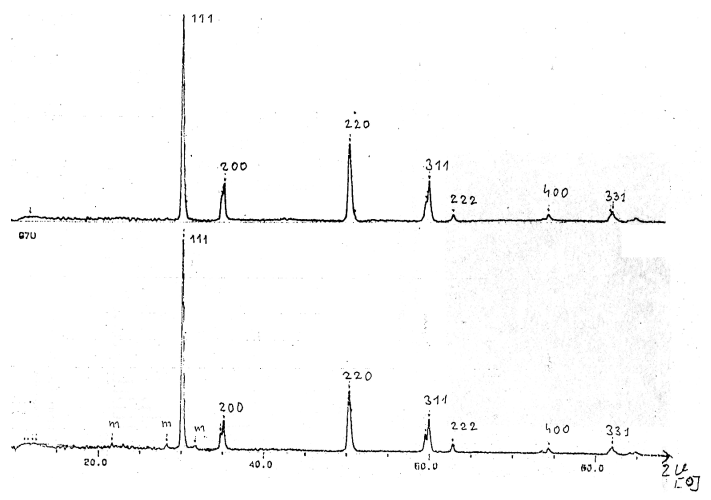

Fig. 7. X-ray diffraction patterns for $\mathrm{ZrO}_{2}+8 \% \mathrm{Y}_{2} \mathrm{O}_{3}$ coating, upper - as sprayed, lower - after 60 thermal shocks, m - monoclinic phase.

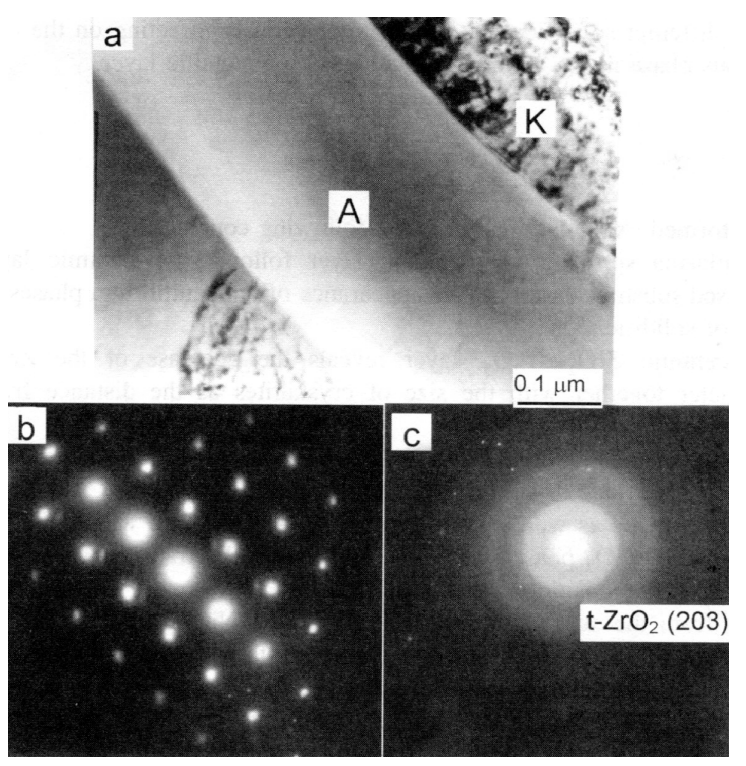

Fig. 8. (a) TEM microstructure of $\mathrm{ZrO}_{2}-\mathrm{Y}_{2} \mathrm{O}_{3}$ coating, (b) SAED pattern for the area K, (c) SAED pattern for the area A.

TEM-SAED studies give similar results as in previous composites with the slight differences. Layered microstructure with slight deviations in chemical and phase composition appear. An example of neighboring amor- phous and crystalline areas is shown in Fig. 8. Figure 8a shows elongated form about $500 \mathrm{~nm}$ thick (marked by A) recognized as mainly amorphous (diffraction pattern in Fig. 8c). Visible rings correspond to fine crystalline tetragonal $\mathrm{ZrO}_{2}$. The pattern in Fig. $8 \mathrm{~b}$ shows ordered crystalline forms: cubic and tetragonal. Annealing causes some ordering changes with among others decreasing amorphous areas which become fine crystalline and partial dissolving of columnar crystals in matrix of equiaxial crystals.

\section{Concluding remarks}

Two groups of composites as ceramic components of TBC coatings were studied. Phase transitions and microstructure changes in the results of plasma spraying process and subsequent thermal treatment are determined. Coatings show specific layered structure. These layers may locally differ from each other in phase and chemical composition. Near the interface with metallic bondcoat more amorphous and nanocrystalline areas appear, but fine crystalline areas are also encountered. Nearer to the coatings interior mostly crystalline areas more or less ordered are observed with some columnar crystals agglomerations. Annealing causes changes towards ordering with the extent depending on searched composite. The amorphous areas occurring is confirmed by increase of background level in X-ray diffraction patterns.

According to some opinions the degree of amorphisation for particular composites is dependent among others on components atomic sizes [14].

The observed effects are caused mainly by the conditions of plasma spraying process distant from thermodynamic equilibrium.

Turning to some practical results meaning the aims for both studied material groups differ slightly from each other. For $\mathrm{ZrO}_{2}$ group, where stabilisation effects are already known, works are directed to choice composite with highest resistance as thermal barrier. PSZ-type composites with $7-8 \% \quad \mathrm{Y}_{2} \mathrm{O}_{3}$ resistant (with slight changes) to more than 100 thermal shock cycles seems to be suitable.

For $\mathrm{Al}_{2} \mathrm{O}_{3}$ group effect of stabilisation is till now not known therefore the attempt of experiments with some addition was important. The results for listed composites are more or less satisfactory but the main result was finding of $\mathrm{Al}_{2} \mathrm{TiO}_{5}$ and studying of its valuable properties for TBC. Coatings with $\mathrm{Al}_{2} \mathrm{TiO}_{5}$ are resistant as yet for 150 thermal shock cycles. It is worth noting that only in this case experiments with thermal shocks cause the same ordering changes as annealing.

The results for $\mathrm{Al}_{2} \mathrm{O}_{3}+\mathrm{ZrO}_{2}$ composite are also promising due to its properties and possibility of linking two basic ceramic oxides.

On the basis of described works the following conclusions may be pointed out:

1. Phase transitions and layered partly disordered coatings microstructure with alternate layers of 
various degree of crystallinity are caused mainly by the plasma spraying conditions.

2. Coatings microstructure and resistance are to some extent dependent on plasma spraying parameter which is important from application point of view.

3. In the $\mathrm{Al}_{2} \mathrm{O}_{3}$ group the highest resistance as thermal barrier shows coatings with $\mathrm{Al}_{2} \mathrm{TiO}_{5}$.

4. In the $\mathrm{ZrO}_{2}$ group highest resistance shows coatings with $7-8 \% \quad \mathrm{Y}_{2} \mathrm{O}_{3}$.

\section{References}

[1] S. Stecura, Am. Ceram. Soc. Bull. 56, 1082 (1977).

[2] A.H. Nicoll, B. Gruner, Surf. Eng. 1, 11 (1985).

[3] H.J. Brandon, R. Taylor, Surf. Coat. Technol. 50, 141 (1982).

[4] L. Górski, Acta Phys. Pol. A 96, 275 (1999).

[5] L. Górski, Report of the IAE, A-47/1999; L. Górski, A. Pawłowski, Diffraction and Microscopic Study on the Structure of Plasma Sprayed Coatings, Monograph of the IAE, in press.
[6] W. Wołczyński, A. Kloch, A. Pawłowski, Bull. Acad. Pol. Sci., Ser. Tech. 50, 181 (2002).

[7] H.A. Thomas, B. Stevens, Br. Ceram. Trans. J. 88, 144 (1989).

[8] A. Pawłowski, M. Faryna, J, Morgiel, L. Górski, Arch. Metall. Mater. 53, 679 (2008).

[9] A. Pawłowski, J. Morgiel, L. Górski, W. Baliga, Arch. Metall. Mater. 53, 989 (2008).

[10] L. Górski, A. Pawłowski, Solid State Phenom. 130, 297 (2007)

[11] A.M. Limurga, S. Widjaja, Mater. Lett. 57, 628 (2002).

[12] X. Miao, B. Ben-Nissan, J. Mater. Sci. 35, 497 $(2000)$.

[13] X. Miao, B. Ben-Nissan, J. Mater. Sci. 35, 497 (2000).

[14] A. Pawłowski, J. Morgiel, T. Czeppe, Arch. Metall. Mater. 52, 635 (2007). 